\title{
The Geomagnetic Non-Dipole Field in the Pacific
}

\author{
Takesi YUKUTAKE* \\ Earthquake Research Institute, University of Tokyo, Bunkyo-ku, Tokyo 113, Japan
}

(Received January 8, 1993; Revised June 20, 1993; Accepted June 26, 1993)

The core-mantle boundary below the Pacific is one of the most interesting regions for the study of the Earth's core because of the phenomena which seem to be characteristic to this region. The geomagnetic phenomeno is one of them. Two features are widely believed to exist in the geomagnetic field in this region. One is absence of the non-dipole field, and the other is its small secular variation, which might be related to special structures of the core-mantle boundary region below the Pacific.

This paper re-examines historical data of declination, and suggests that an intense focus of the non-dipole field existed in the North Pacific in the 17th century, and concludes that the absence of the non-dipole field as seen at present has not been a permanent feature of the magnetic field in the Pacific, implying that the Pacific region is no special region in this sense.

\section{Introduction}

Recent progress in the study of the core mantle boundary has disclosed its nature as being very inhomogeneous geophysically and geochemically. One example is the region below the $\mathrm{Pa}$ cific. Seismic tomography suggests an undulation of the boundary, although arguments about its amplitude is not yet settled whether it is as thick as several kilometers (e.g., MoRELLI and DzIEWONSKI, 1987) or much smoother (e.g., Doornbos and Hilton, 1989). Below the central part of the Pacific, it is supposed that the boundary could be shallower than the peripheral regions. Geodetic studies also requires deviation of the core-mantle boundary from its hydrostatic figure (HAGER et al., 1985; GWINN et al., 1986). Temperature distribution is also unlikely to be uniform at the surface of the core, reflecting the fluid convection inside the core (e.g., BLOXHAM and GubBins, 1987; GubBins, 1988). $\mathrm{D}^{\prime \prime}$ layer at the bottom of the mantle is considered to be particularly inhomogeneous from studies of seismic ray paths and analyses of the Earth's free oscillation (Dziewonski, 1984; Doornbos and Hilton, 1989; Kumagai et al., 1992). The inhomogeneous nature of the core-mantle boundary causes anomalous features in the geophysical phenomena observed at the surface of the Earth. Geomagnetic phenomenon is one of them, which are sensitively influenced by the core-mantle structure.

If the undulation of the core surface is as suggested above, namely that the core-mantle boundary below the central Pacific is shallower, surrounded by a peripheral rim protruding into the core, fluid motions at the core surface below the Pacific region may have particular features, isolated from the regions outside the circum-Pacific rim. From paleomagnetic studies of volcanic rocks in Hawaii, DOELL and Cox (1972) considered that the geomagnetic secular variation in the Pacific was suppressed over geologic time and that the geomagnetic field was so simple as at present that the irregular non-dipole field did not exist. Two causes would be conceivable for this. One is that these might be caused by particular flows near the core surface characteristic to the topography of the core mantle boundary below the Pacific region. The other possible interpretation of the small secular change would be a strong attenuation of the geomagnetic variation

\footnotetext{
* Now at Department of Earth and Planetary Sciences, Kyushu University, Hakozaki, Fukuoka 812, Japan.
} 
through a conducting region of the mantle. If the electrical conductivity is particularly high below the Pacific, the geomagnetic variations originated from the core will be seriously attenuated while propagating through this conducting part of the mantle. $\mathrm{D}^{\prime \prime}$ layer is now regarded as a compositional boundary layer as well as a thermal boundary layer, where the content of iron is high and temperature is also high in comparison with other part of the mantle. Rich iron content and high temperature both increase the electrical conductivity. Hot plumes which are supposed to rise from the $\mathrm{D}^{\prime \prime}$ layer and form hotspots in the central Pacific also increase the conductivity below the central Pacific.

Examining the correlation between the Earth's gravitation and magnetic fields, Hide and MALIN (1970) and MALIN and HIDE. (1982) considered that fluid flow near the core surface was disturbed by the topography of the core-mantle boundary, and the disturbance propagated westwards as magnetostrophic waves that were observed as the westward drift of the magnetic field. GubBINs (1991) discusses that the westward flow may be blocked at the eastern periphery of the circum-Pacific rim and divided into poleward flows, which are to confine the paleomagnetic polar paths at the time of polarity transition to a particular meridian passing through the American continent.

Many of these arguments about the particular features of the core flows below the Pacific region are partly based on the seismic tomography and partly on the geomagnetic variations. Whether the geomagnetic field over the Pacific is different from other areas or not is, therefore, an important question for discussing the fluid dynamics at the core surface. This paper re-examines the nature of the geomagnetic field in the Pacific area.

\section{Two Characteristic Features of the Geomagnetic Field in the Pacific}

It has been believed fairly widely that there are two features characteristic to the geomagnetic field over the Pacific. One is that the non-dipole field has long been small and the dipole field has predominated in this area. The other is that the secular variations in the Pacific has been small over geologic time.

When the recent geomagnetic field is examined, it is noted that the non-dipole field is small in the North Pacific as seen in Fig. 1. This implies that the major part of the magnetic field in this area is that of the geomagnetic dipole and its secular change reflects the dipole change. In this view the Pacific is regarded as a window through which one may see the change in the dipole field, which is usually concealed, in other areas, by rapid changes in the non-dipole field. The present feature of the non-dipole field in the Pacific is seen to have persisted since sometime around 1770 A.D. (YukUtake and TaChInAKa, 1968). Delineating the magnetic field at the core-mantle boundary by a downward continuation from surface data, BLOXHAM et al. (1989) also noticed that the magnetic field below the North Pacific had not changed appreciably since 1715 and considered that the changing part of the magnetic field was generated near longitude $120^{\circ} \mathrm{E}$ and drifted westwards to disappear near longitude $90^{\circ} \mathrm{W}$.

Paleomagnetic investigation of Hawaiian lava flow indicates that the angular dispersion of the geomagnetic virtual pole is remarkably small. Assuming that the dispersion of the pole position around its mean is caused by the secular variation in the geomagnetic field, DoELL and Cox (1972) interpreted this small dispersion as a result of a small secular variation in Hawaii, which might be caused mainly by the dipole change and contributed little from the non-dipole field. And this lead them to infer that the small non-dipole field in the North Pacific as seen in the present configuration of the geomagnetic field had persisted over geologic times.

However, MCELHINNY and MERRILL (1975) suspected that, in spite of huge volume of samples Doell and Cox collected, lavas from which they were taken might possibly be erupted for so short a period of time that might not be sufficient to represent the long period nature of the geomagnetic secular variations. Examining the lavas in Hawaii with ages back to 18,000 years 


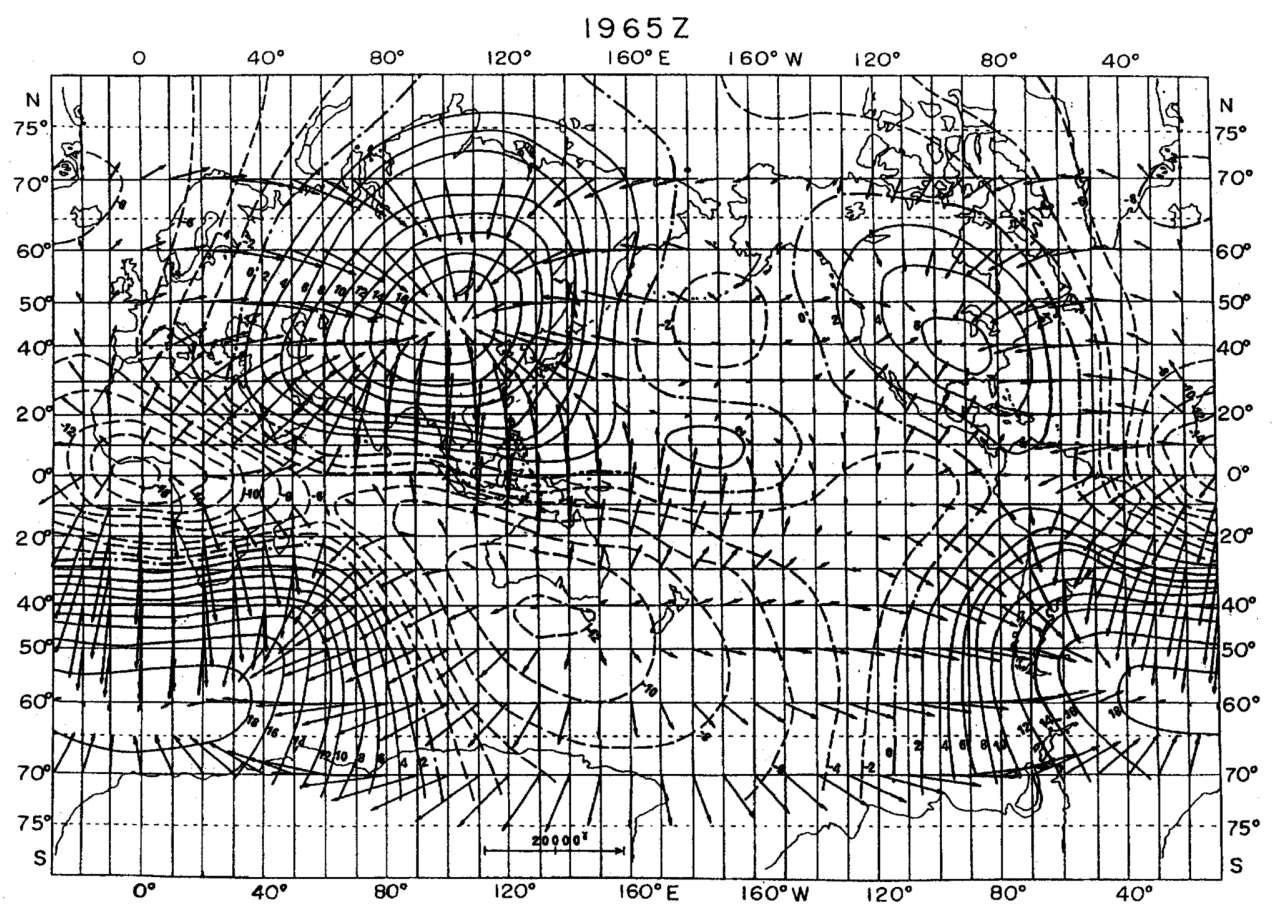

Fig. 1. The non-dipole part of the vertical component of the geomagnetic field at the surface of the Earth for 1965 (YUKUTAKE and TACHINAKA, 1968). Contour intervals are $2000 \mathrm{nT}$. Vector represents horizontal components of the non-dipole field. The field is relatively weak in the North Pacific.

before present, COE et al. (1978) obtained a larger angular dispersion of the paleomagnetic pole, and inferred that a significant size of the non-dipole field had existed in the area of Hawaii a few thousand years before. Lately, however, the investigation was extended to well-dated lavas (MCWilliams et al., 1982) and to lake sediments (Peng and King, 1992) in Hawaii to find that the angular dispersion had been small over the past few tens of thousands of years. On the other hand, examinations of the observatory data since around 1900 A.D. have revealed appreciable secular change (HINATA and YUKUTAKE, 1992) and secular acceleration (SKINNER, 1981) at Honolulu, which are very similar to those at Apia. The question whether the secular variation in the North Pacific was small or not has not yet been completely settled.

On the other hand, there is a suggestion that a strong non-dipole field existed in the North Pacific when one goes back to around 1650 A.D. YUKUTAKE and TACHINAKA (1968) synthesized non-dipole field for 1650 A.D. from spherical harmonic coefficients (FRITSCHE, 1900; YUKUTAKE, 1971) that were derived from declination and inclination data. Figure 2 is a chart of the nondipole vertical component (YUKUTAKE, 1971). Different from the non-dipole chart for 1965, this figure shows an intense focus in the central part of the North Pacific. An argument was raised by DoELL and Cox (1972) against the reality of the non-dipole focus in the Pacific simply because the number of measurements had been so scarce at this time that the non-dipole field shown in the figure was not convincing.

In this paper the data for the early 17 th century are re-examined, which has resulted in that the existing data, although the number is limited, give support for the existence of the non-dipole focus in the North Pacific. 


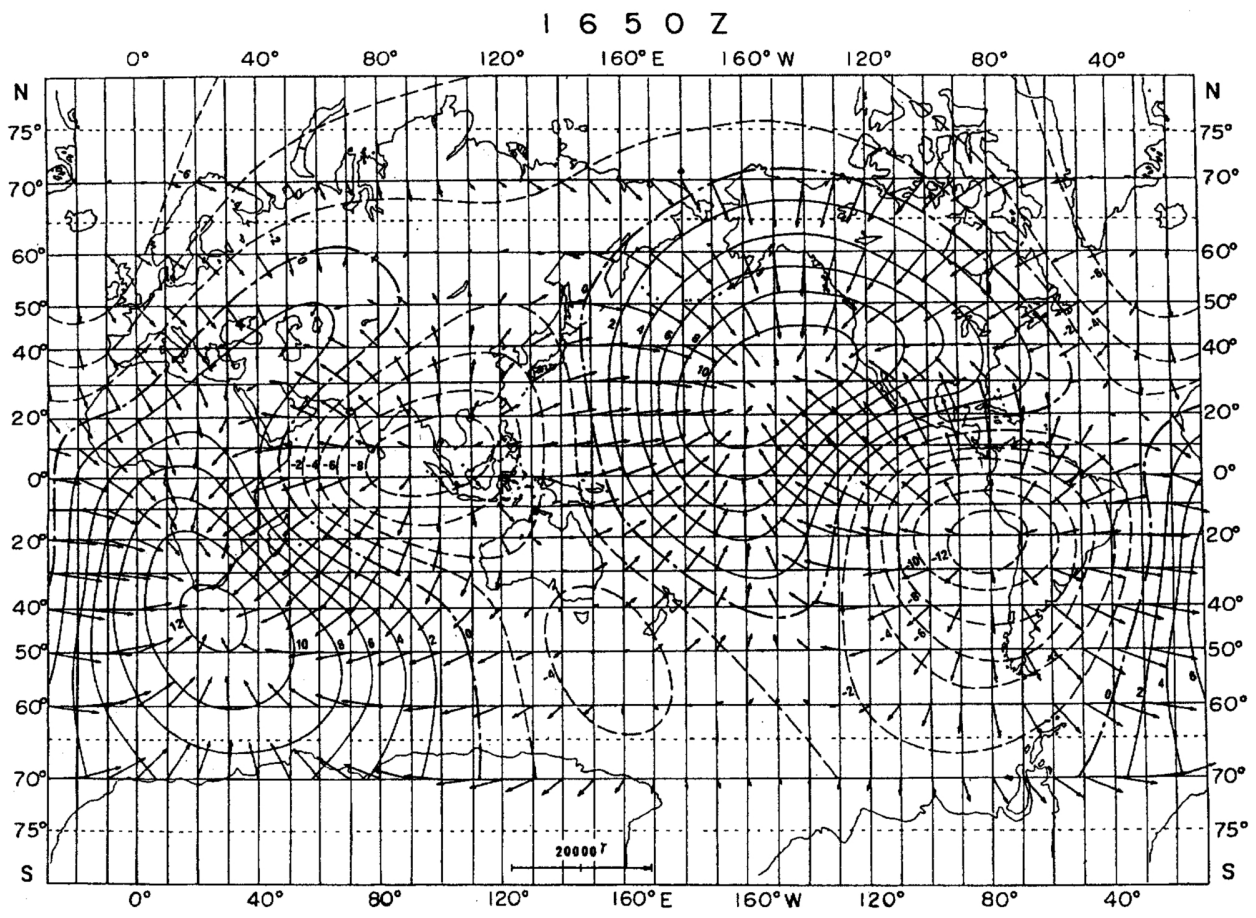

Fig. 2. The non-dipole part of the vertical component of the geomagnetic field at the surface of the Earth synthesized from a field model for 1650 (YuKuTAKe, 1971). An intense non-dipole focus exists in the Pacific.

\section{Spatial Distribution of Declination Suggestive of the Non-Dipole Focus}

Suppose a positive focus of the non-dipole vertical component where the magnetic lines of force converge as in Fig. 3. Then the magnetic declination becomes positive (eastward) in the west of the focus, and negative (westward) in the east. It is also noted that the inclination becomes maximum at the focus. Figure 2 shows a positive focus located at about $25^{\circ} \mathrm{N}$ and $155^{\circ} \mathrm{W}$ in 1650 . If this is real, the declination must have been eastward in the west of the focus and westward in its east.

VAN BEMMELEN (1899) compiled the declination and the inclination data so far existing, and gave gridded values of declination at $10^{\circ}$ intervals of longitude and latitude. A declination chart delineated on these gridded values for 1600 is shown in Fig. 4. A pair of positive and negative foci are clearly seen to be aligned in the east-west direction, with a positive maximum declination to the west, around $170^{\circ} \mathrm{E}$ and a negative minimum to the east, around $130^{\circ} \mathrm{W}$. This suggests existence of a positive focus of the non-dipole vertical component between these maximum and minimum, which is consistent with the non-dipole features shown in Fig. 2.

Recent declination in the Pacific is very different as shown in Fig. 5 from that in 1600 A.D. No such a remarkable pair of maximum and minimum declination exist in the Pacific, which is consistent with the smallness of the non-dipole field in this area.

A question arises whether or not the spatial data coverage is sufficient to substantiate the existence of the pair of positive and negative declination for the early 1600s. Data points are also indicated by solid circles at grid points, which means that more than a single measurement were conducted within $\pm 5^{\circ}$ in longitudes and latitudes surrounding the solid-circled grid point. It is seen that data were acquired almost at every $10^{\circ}$ intervals in longitude along two parallels 


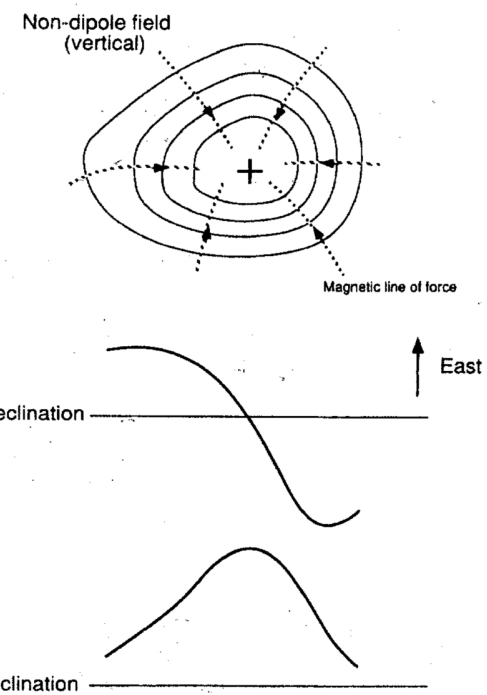

Fig. 3. Declination and inclination profiles across the center of the non-dipole focus of the vertical component. The declination is east in the west of the focus, whereas it is west in its east. The inclination becomes a maximum at the focus.

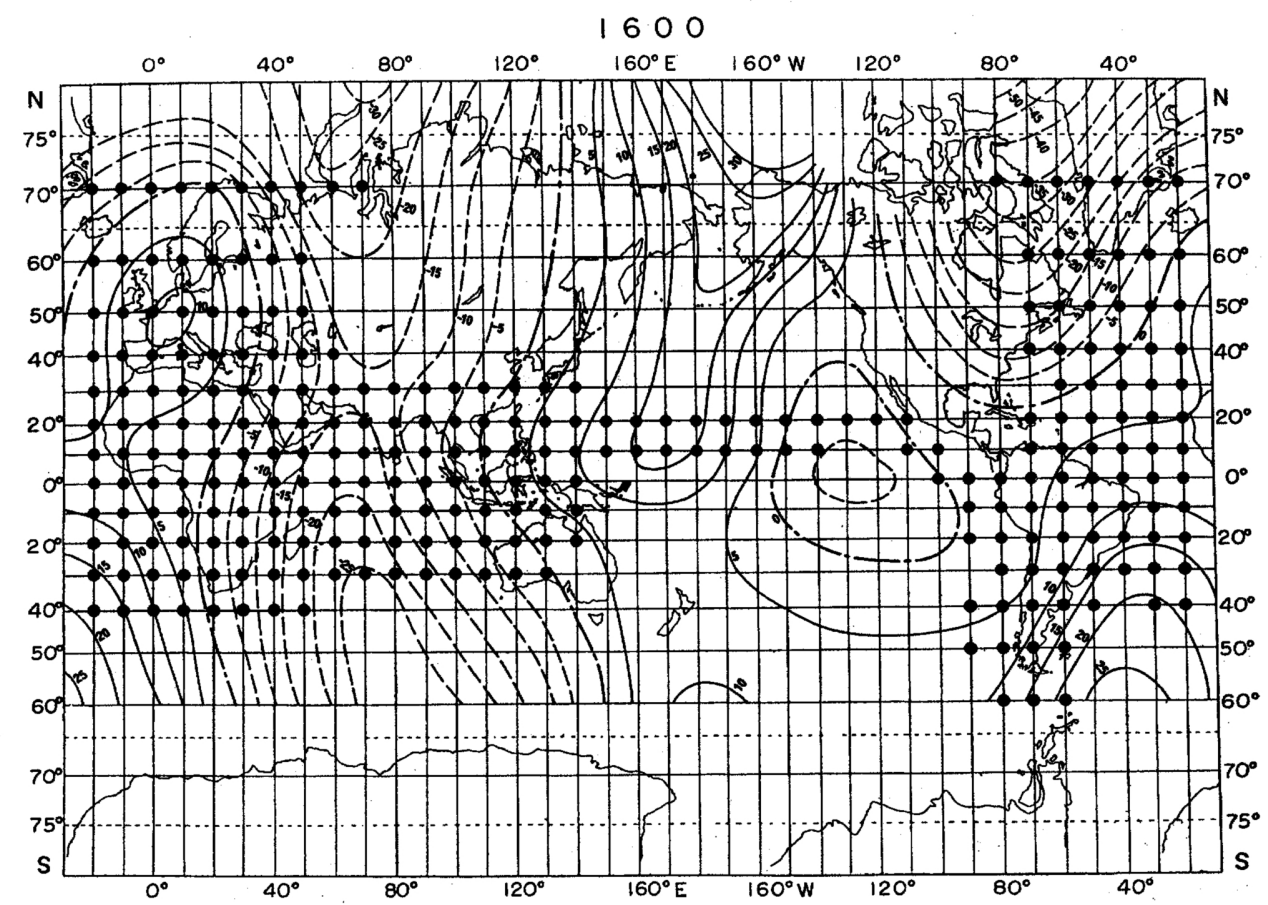

Fig. 4. Declination chart for 1600 reproduced from VAN BEMMELEN (1899). Data points are shown by solid circles at grid points, indicating that more than a single measurement were conducted within $\pm 5^{\circ}$ in longitudes and latitudes surrounding the solid-circled grid point. 


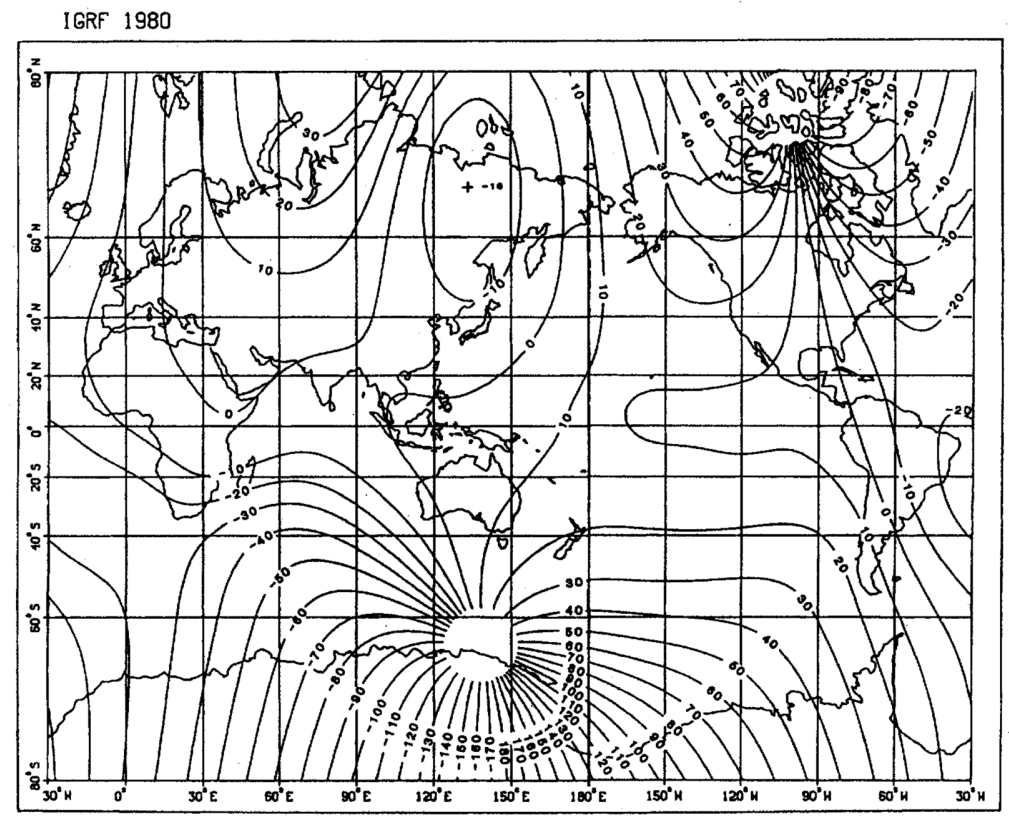

Fig. 5. Declination chart for 1980 (FABIANo et al., 1983).
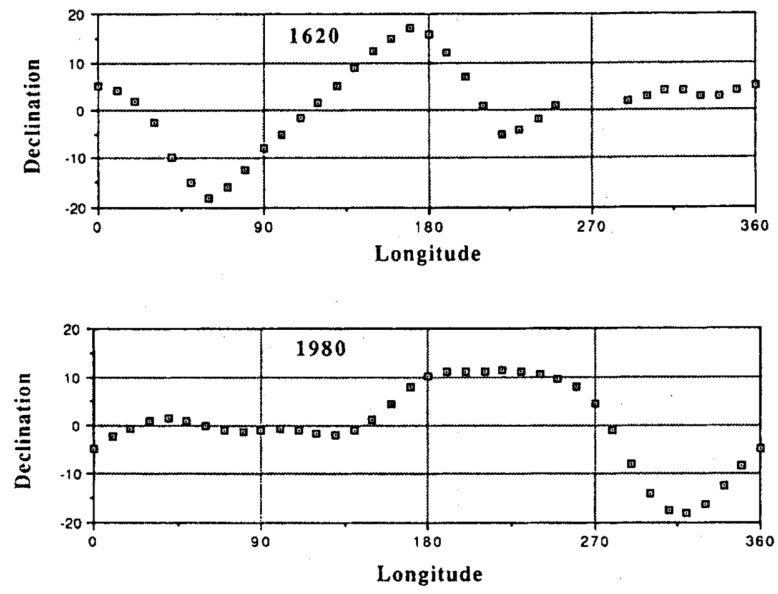

Fig. 6. Declination along a parallel circle of $20^{\circ} \mathrm{N}$ for 1620 plotted from VAN BemMELEN (1899) and that for 1980 .

of $10^{\circ} \mathrm{N}$ and $20^{\circ} \mathrm{N}$. Figure 6 is the plots of declination for 1620 along a parallel circle of $20^{\circ} \mathrm{N}$ in comparison with the present declination. At the longitude of $170^{\circ} \mathrm{E}$, the declination is as large as $18^{\circ} \mathrm{E}$, whereas it is $-6^{\circ} \mathrm{E}$ at the longitude $220^{\circ} \mathrm{E}\left(140^{\circ} \mathrm{W}\right)$. The zero declination is seen around $210^{\circ} \mathrm{E}$, which suggests existence of a positive focus of the vertical component near this longitude. The feature is very different from that for 1980 .

Cruise records of magnetic measurements by ships are also in VAN BEMMELEN (1899). Fig- 

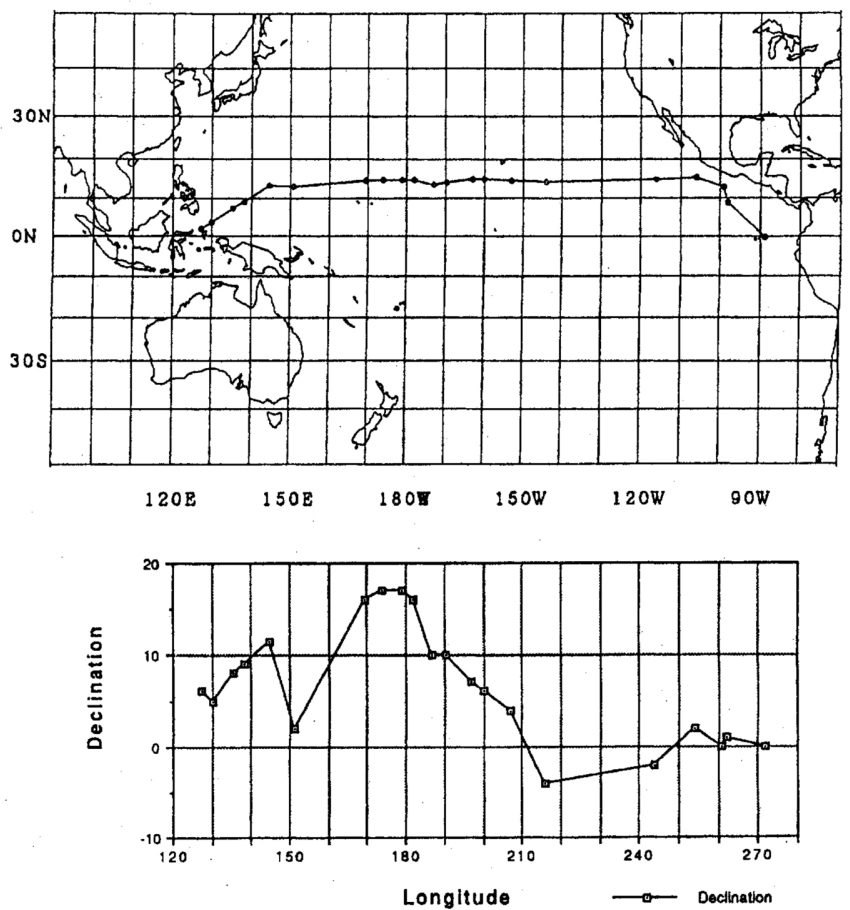

Fig. 7. Declination measurements conducted by J. L'Hermite in 1624 and 1625 . The upper diagram shows the cruise course of the magnetic measurements with solid circles indicating the measuring sites. The lower diagram is the results for declination. Accuracy of the measurements is not known, but must be slightly better than $1^{\circ}$, since the data are given at intervals of 30 minutes of arc. The data for $\left(13^{\circ} 10^{\prime} \mathrm{N}, 151^{\circ} \mathrm{E}\right)$ is commented in VAN BEMMELEN (1899) to be an error, and must be $12^{\circ}$. The maximum deviation of the east declination is seen around $170^{\circ} \mathrm{E}$, and that of the west declination around $220^{\circ} \mathrm{E}$. It is very likely that a positive focus of the vertical component which attracts the magnetic lines of force was located somewhere around $210^{\circ} \mathrm{E}$ in 1624 .

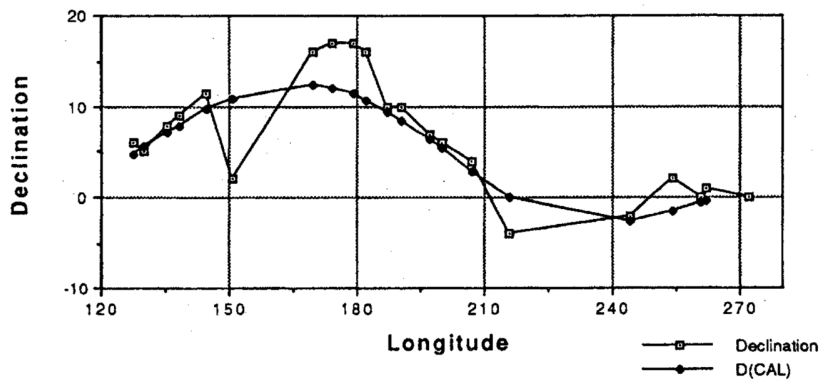

Fig. 8. Comparison of declinations computed from the field model for 1625 with those observed by J. L'Hermite in 1624 and 1625 . 
ure 7 shows a cruise course of magnetic measurements conducted by J. L'Hermite in 1624 and their results of declination. He started his measuring cruise at $\left(0^{\circ} \mathrm{N}, 88^{\circ} \mathrm{W}\right)$ on September 20 , 1624 , and ended at $\left(1^{\circ} \mathrm{S}, 127.5^{\circ} \mathrm{E}\right)$ on March 30,1625 . The places where the measurements were conducted are plotted by solid circles. The results of the measurements are shown in the lower diagram. The maximum deviation of the east declination is seen around $170^{\circ} \mathrm{E}$ again, and that of the west declination around $220^{\circ} \mathrm{E}$. It is very likely that a positive focus of the vertical component which attracts the magnetic lines of force was located somewhere around $210^{\circ} \mathrm{E}\left(150^{\circ} \mathrm{W}\right)$ in 1624 . Such a positive focus is well represented in the non-dipole chart of the vertical component in Fig. 2.

Figure 8 shows how well the spherical harmonic field model, which gives the non-dipole vertical component in Fig. 2, approximates the observed declination. Solid circles are the declination computed for the observation sites of the cruise. The field model for 1625 was constructed by a linear interpolation between those for 1600 and 1650 .

\section{The Non-Dipole Low since 18th Century}

The absence of the non-dipole field in the Pacific becomes noticeable since mid-18th century. The strong focus of the non-dipole vertical component has disappeared from the North Pacific since 1770 at latest (YuKUTAKE and TACHINAKA, 1968). The disappearance of the non-dipole focus is consistent with the data of the change in the declination. Figure 9 shows how the declination profile along the parallel circle of $20^{\circ} \mathrm{N}$ has changed with time since 1700 . The Pacific region ranges from $140^{\circ} \mathrm{E}$ to $270^{\circ} \mathrm{E}$ approximately. In 1980 the declination is almost flat between $180^{\circ} \mathrm{E}$ and $270^{\circ} \mathrm{E}$. This implies that the vertical component does not change appreciably along the parallel over the Pacific region. This feature of the declination in the Pacific region is similar back to 1770 .

However, when compared with earlier declination, it is seen that the declination profile for 1620 is very different from that after 1770. This explains why appearance of the non-dipole vertical component over the Pacific is so different between 1620 and after 1770 .

\section{Secular Variation in Declination in Japan}

Another evidence supporting the existence of the intense non-dipole focus in the Pacific in the 17 th century is seen in the secular variation data in declination in Japan. Existence of such a focus in the east of Japan deflects the magnetic lines force towards east, causing the declination eastwards.

Figure 10 shows the variation in the declination at Tokyo (IMAMITI, 1956). In mid-1600s the declination was east, as large as $7^{\circ} \mathrm{E}$, whereas it is about $6^{\circ} \mathrm{W}$ in mid-1900s. This feature is consistent with the declination distribution seen in the chart for 1600 in Fig. 4 and that for 1980 in Fig. 5. It is considered that the magnetic field was deflected towards east by a strong non-dipole focus in the Pacific in 1600s, while it is towards west at the present time by an intense non-dipole anomaly covering the wide area of the Asian continent.

The change of the declination from eastwards to westwards is supposedly caused by a westward drift of the non-dipole focus which was situated in the Pacific in the 1600s. YUKUTAKE and TACHINAKA (1969) found that the geomagnetic field consisted of two parts, standing and drifting fields. The standing field stays almost at the same place over several hundred years without changing its shape and intensity, while the drifting field drifts westwards steadily with a constant velocity, about $0.3^{\circ}$ year. This nature of the geomagnetic field has been confirmed lately by BLOXHAM et al. (1989).

YUKUTAKE and TACHINAKA (1969) found that the standing field in the North Pacific is small, whereas an intense positive anomaly of the non-dipole vertical component covers the Asian 

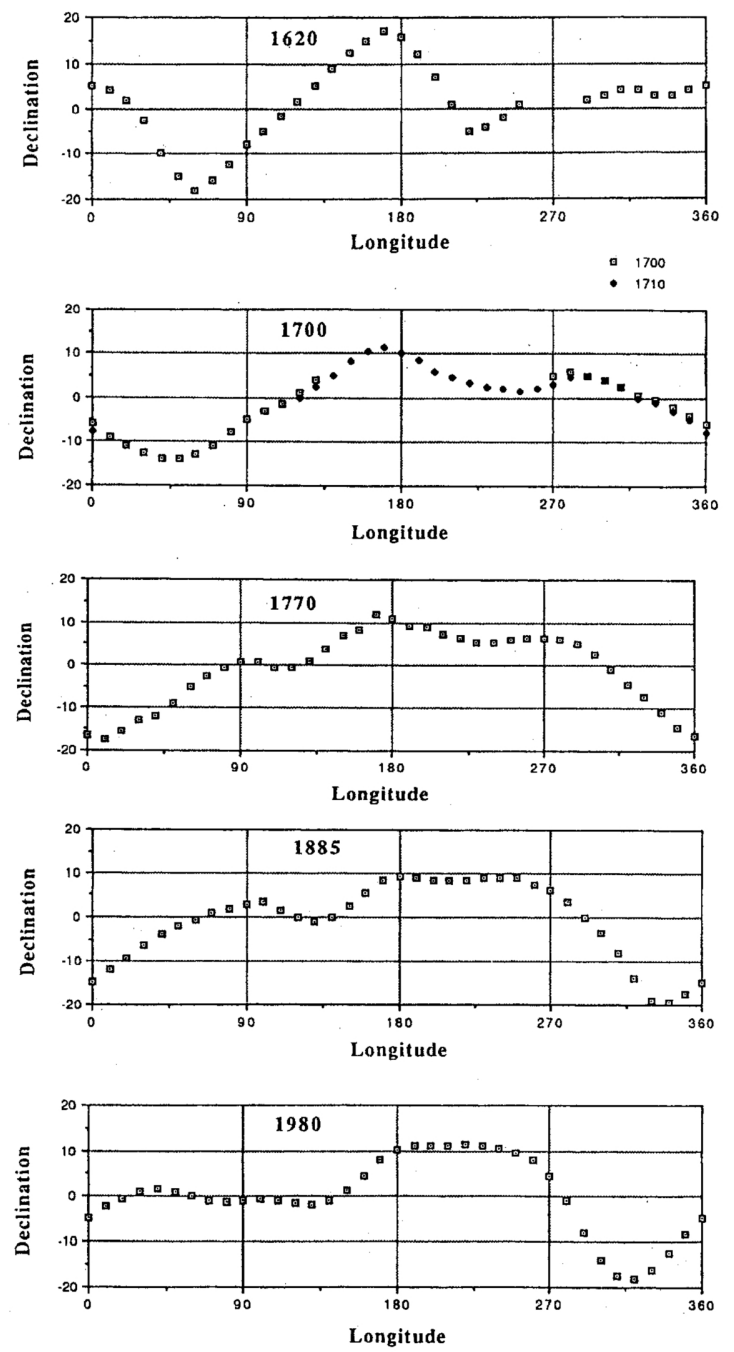

Fig. 9. Change in the declination profile with time. Declination profiles are along the parallel circle of $20^{\circ} \mathrm{N}$. The Pacific region ranges from $140^{\circ} \mathrm{E}$ to $270^{\circ} \mathrm{E}$ approximately. In 1980 the declination is almost flat between $180^{\circ} \mathrm{E}$ and $270^{\circ} \mathrm{E}$, implying that the vertical component does not change appreciably along the parallel over the Pacific region. This feature of the declination in the Pacific region is similar back to 1770.

continent. With this configuration of the non-dipole anomaly, namely under the influence of the anomaly covering the Asian continent, Japan is located in an area of the west declination in the mean, when taken over such a long time as the effect of the drifting field is averaged out. However, the drifting part had a positive focus in the North Pacific in 1600s to produce the intense focus of the total non-dipole field in this region as in Fig. 2, when synthesized together with the standing field. On the other hand, the Asian continent was a negative area of the drifting field at this time, which caused the Asian continent to be a neutral area, superposed on the positive standing field. Accordingly as the positive focus of the drifting field in the North Pacific, which made the declination in Japan eastwards, moved to the west and merged into the positive standing field in the Asian continent, the declination in Japan changed from east to west. In this way the change 


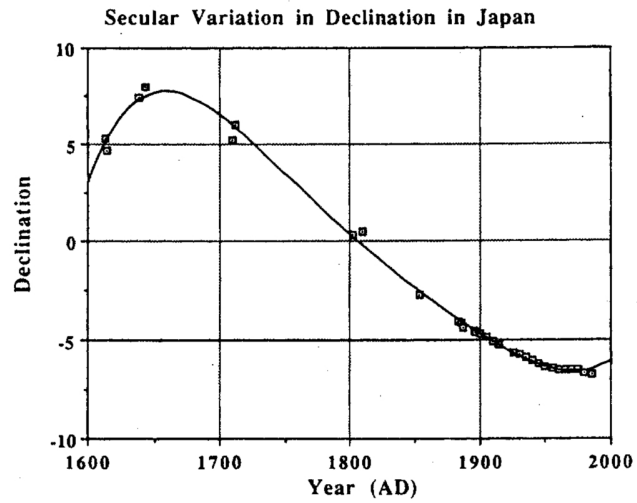

Fig. 10. Variation in the declination at Tokyo (IMAMITI, 1956).

of declination in Japan from east to west is understood by the westward drift of the non-dipole field whose focus was located in the North Pacific in the mid-1600s.

\section{Secular Variations in Declination and Inclination in Hawaii}

Secular variation data in Hawaii provide an important clue to solve the question whether or not the non-dipole focus existed in the North Pacific in 1600s. If such a non-dipole vertical focus existed, the magnetic inclination must have been a maximum as illustrated in Fig. 3, and the declination small, nearly zero.
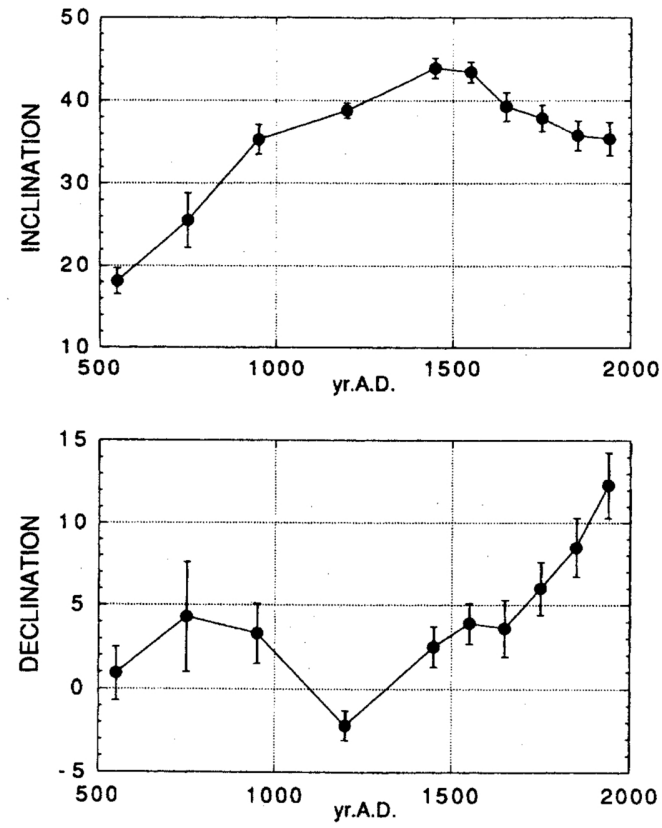

Fig. 11. Secular variations in declination and inclination in Hawaii obtained by paleomagnetic studies of volcanic rocks (Holсомв et al., 1986). Error bars represent angles for $\alpha_{95}$, the circle of $95 \%$ confidence of the mean. A remarkable feature is a maximum in the inclination around 1500 A.D. 
Pleomagnetic studies on Hawaiian lavas (HolCOMB et al., 1986) reconstructed the secular variations in declination and inclination in Hawaii back to 6000 years before the present. Figure 11 shows a part of their results, plotting the data since 500 A.D. A remarkable feature is a maximum in the inclination around 1500 A.D. This is consistent with the model that a positive focus of the non-dipole vertical component passed through this region from east to west. Corresponding to the maximum in the inclination, the declination was small around 1500 A.D. This appears to be also consistent with the drifting focus model.

However, the interpretation of the declination is not so straightforward as in the case of the inclination. When the positive focus moved from east to west, the declination is expected to change from eastwards to westwards as seen in Japan. Figure 11 shows that the declination has increased its eastward deviation since around 1500 A.D. This is opposite from what is expected by the westward drift. Presumably this is caused by the predominance of the dipole component, the axial plus the equatorial dipole. As the focus moved on to further west, the influence of the non-drifting equatorial dipole is supposed to have become more predominant to cause the eastward declination.

Although there remains certain ambiguity with the declination data, the secular change in the inclination obtained from Hawaiian lavas also give support for the model that the intense non-dipole focus exited in the North Pacific several hundred years ago.

\section{Geophysical Significance of the Existence of the Non-Dipole Focus in the Pacific Region}

The core-mantle boundary and the $\mathrm{D}^{\prime \prime}$ layer are likely to be more inhomogeneous than considered before. Those below the Pacific are the region suspected to have different nature from other part on the basis of seismic and geomagnetic data. One of the bases from which the suspicion stems is the inference that the non-dipole field has been small in the Pacific.

Since a large part of the geomagnetic secular variation is caused by the non-dipole field rather than by the dipole field, the absence of the strong non-dipole field in the North Pacific at present time is supposed to cause small secular variation in this area. On the other hand, information on the secular variation over geologic time is obtained from paleomagnetic studies. Small angular dispersion of the virtual geomagnetic pole position derived from Hawaiian lavas was interpreted by DoELL and Cox (1972) that the secular variation had been small in Hawaii over geologic time and that the small secular variation was a manifestation of the dipole change without contribution from the non-dipole field, requiring that the non-dipole field had been absent in the area of Hawaii for such intervals.

If these were true, such a scenario would be derivable as that the core surface below the Pacific is a special region which extinguishes the near surface magnetic field. This phenomenon could be due to a particular type of fluid motion confined in a region surrounded by a circumPacific rim where the mantle is protruded into the core. The fluid motion could be, for instance, such as a stagnant motion, isolated from other part, and no strong non-dipole field could be generated. Magnetic disturbances can be created only at the peripheries. Those generated at the western periphery of the circum-Pacific rim propagate westwards, and travel around to reach the eastern periphery, where the disturbances are blocked to disappear. In this way, magnetic disturbances are neither created inside the region surrounded by the rim nor transmitted into this region from outside.

However, historical data presented in this study are obviously unfavorable for the above scenario. Because they indicate that a strong non-dipole focus existed in the Pacific region, and drifted westwards. Therefore the region cannot be a special region where the magnetic field dies out. Furthermore it is difficult to say that the secular variation was small in this region as far as historic data are concerned, because the westward drift of the non-dipole focus causes an appreciable secular variation. 


\section{Concluding Remarks}

Re-examination of the historic data in the 17th century strongly suggests existence of an intense non-dipole focus in the North Pacific in mid-1600s. Magnetic measurements conducted on the way of voyage along a parallel circle of latitude $20^{\circ} \mathrm{N}$ from $88^{\circ} \mathrm{W}$ to $127^{\circ} \mathrm{E}$ for 1624 to 1625 indicates that the magnetic declination changed from west to east around $150^{\circ} \mathrm{W}$. This suggests existence of a magnetic focus some place around $150^{\circ} \mathrm{W}$ in the low latitude on which the magnetic lines of force converges. This is very different from the present distribution of the declination which is characteristic of non-existence of the non-dipole focus.

Secular variation in declination in Japan and that in inclination in Hawaii also supports the existence of the non-dipole focus in the North Pacific in the 17th century. Furthermore these data are consistent with the drifting field model that the focus is of the drifting type and that it has moved westwards from the North Pacific to the Asian continent during 300 years from mid-1600s to mid-1900s.

In the 17th century, the declination was largely towards east in Japan, whereas it is towards west at present. A positive focus of the non-dipole field located in the east of Japan in the 17th century is considered to have caused the magnetic field direction to deviate towards east, whereas a positive focus now existing in the Asian continent makes the magnetic declination west in Japan. A maximum inclination observed in the 16th century in Hawaii is also consistent with the drifting model. Since an increase in the vertical component deepens the dip angle of the magnetic field, a maximum of inclination is expected to occur when a positive focus of the vertical component had passed through the Hawaiian area.

Although the non-dipole field is so small in the North Pacific at present that the secular variation may solely reflect the behavior of the dipole field, this paper concludes that this can never be a permanent feature in this area. The North Pacific is supposed to have been covered with an intense non-dipole focus in mid-1600s, and it is possible for this area to be covered with another positive focus again in several hundred years. As a consequence, the secular variation of the magnetic field cannot be small. Therefore, as far as the historic time is concerned, going back to several hundred years, we may say that the Pacific is not such a special area where the non-dipole field is absent all the time.

The results of this study seem irreconcilable with those of the paleosecular variation studies on Hawaii, as far as the small angular dispersion of the virtual geomagnetic pole reflects the true nature of the secular variations in Hawaii. The existence of the strong non-dipole focus does not necessarily mean a large secular variation, but as discussed above, if this focus is of drifting nature, the secular variation is not small at all, which is in accord with the observed variation for the past several hundred years. On the other hand, the small angular dispersion of the virtual geomagnetic pole for the Hawaiian rocks does not indicate the absence of the non-dipole field by itself, but it can be rather related to small secular variation, provided that the data cover sufficiently long time intervals to represent the statistical nature of the secular variations and that the angular dispersion really reflects the secular change. A possible way to reconcile this conflict may be to consider that the normal secular variation associated with the intense nondipole anomaly is a temporary feature only seen for recent time, while the small secular change is basically the feature characteristic of the Pacific. However, this seems also difficult, because the amplitudes of the secular variation for the past thousand of years which was analyzed in the dispersion study are as large as or rather larger than those instrumentally observed for the recent several hundred years. The question is still left unsolved.

I thank J. C. Cain and M. Kono for their comments on the manuscript, which were very useful in improving the paper. 


\section{REFERENCES}

Bloxham, J. and D. Gubbins, Thermal core-mantle interactions, Nature, 325, 511-513, 1987.

Bloxham, J., D. Gubbins, and A. Jackson, Geomagnetic secular variation, Phil. Trans. Roy. Soc. Lond., 329, 415-502, 1989.

Coe, R. S., S. Gromme, and E. A. Mankinen, Geomagnetic paleointensities from radiocarbon-dated lava flows on Hawaii and the question of the Pacific non-dipole low, J. Geophys. Res., 83, 1740-1756, 1978.

DoEll, R. R. and A. Cox, The Pacific geomagnetic secular variation anomaly and the question of lateral uniformity in the lower mantle, in The Nature of the Solid Earth, edited by E. C. Robertson, pp. 245-284, McGraw Hill, New York, 1972.

Doonnbos, D. J. and T. Hilton, Models of the core-mantle boundary and the travel times of internally reflected core phases, J. Geophys. Res., 94, 15747-15751, 1989.

Dziewonski, A. M., Mapping the lower mantle: Determination of lateral heterogeneity in P velocity up to degree and order 6, J. Geophys. Res., 89, 5929-2952, 1984.

Fabiano, E. B., N. W. Peddie, D. R. Barraclough, and A. K. Zunde, International Geomagnetic Reference Field 1980-Charts and grid values, IAGA Bull, No. 47, 142 pp., 1983.

Fritsche, H., Die Elemente des Erdmagnetismus und Ihre Säcularen Aenderungen wärend des Zeitraumes 1550 bis 1915, St Petersburg, 1900.

Gubbins, D., Thermal core-mantle interactions and time-averaged paleomagnetic field, J. Geophys. Res., 93, 3413-3420, 1988.

GubBins, D., Geomagnetic polarity reversals, presented at the symposium, Major Puzzling Problems or Paradoxes in Contemporary Geophysics, IUGG XII General Assembly, Union Abstracts, p. 25, 1991.

Gwinn, C. R., T. A. Herring, and I. I. Shapiro, Geodesy by radio interferometry: Studies of the forced nutations of the Earth, 2. Interpretation, J Geophys. Res., 91, 4755-4765, 1986.

Hager, B. H., R. W. Clayton, M. A. Richards, R. P. Comer, and A. M. Dziewonski, Lower mantle heterogeneity, dynamic topography and the geoid, Nature, 313, 541-545, 1985.

Hide, R. and S. R. C. MALIN, Novel correlations between global features of the Earth's gravitational and magnetic fields, Nature, 225, 605-609, 1970.

Hinata, K. and T. YuKutAKe, Geomagnetic secular variation near the equator in the Pacific region, Central Core of the Earth, 2, 183-186, 1992 (in Japanese).

Holcomb, R., D. Champion, and M. MCWilliams, Dating recent Hawaiian lava flows using paleomagnetic secular variation, Geol. Soc. Amer. Bull., 97, 829-839, 1986.

IMAMITI, S., Secular variation of the magnetic declination in Japan, Mem. Kakioka Mag. Obs., 7, 49-55, 1956.

Kumagai, H., Y. Fukao, N. Suda, and N. Shibata, Structure of the $D^{\prime \prime}$ layer inferred from the Earth's free oscillations, Central Core of the Earth, 2, 1-18, 1992.

MALin, S. R. C. and R. Hide, Bumps on the core-mantle boundary: geomagnetic and gravitational evidence revisited, Phil. Trans. R. Soc. Lond., A306, 281-289, 1982.

McElhinny, M. W. and R. T. Merrill, Geomagnetic secular variation over the past 5 m.y., Rev. Geophys. Space Phys., 13, 687-708, 1975.

McWilliams, M. O., R. T. Holcomb, and D. E. Champion, Geomagnetic secular variation from ${ }^{14} \mathrm{C}$-dated lava flows on Hawaii and the question of the Pacific non-dipole low, Phil. Trans. Roy. Soc. Lond., A306, 211-222, 1982.

Morelli, A. and A. M. DzIEwONSKI, Topography of the core-mantle boundary and lateral homogeneity of the liquid core, Nature, 325, 678-683, 1987.

Peng, L. and J. W. KIng, A Late Quaternary geomagnetic secular variation record from Lake Waiau, Hawaii, and question of the Pacific nondipole low, J. Geophys. Res., 97, 4407-4424, 1992.

Skinner, N. J., Abrupt changes in secular acceleration of the geomagnetic field in the Pacific, New Zealand J. Geology Geophys., 24, 539-544, 1981.

Van Bemmelen, D. W., Die Abweichung der Magnetnadel, Beobachtungen, Säcular-Variation, West- und Isogonensysteme bis zur Mitte des XVIIIten Jahrhunderts, Royal Magnetical and Meteorological Observatory, Batavia, 1899.

YUKUTAKE, T., Spherical harmonic analysis of the earth's magnetic field for the 17th and 18th centuries, $J$. Geomag. Geoelectr., 23, 11-31, 1971.

Yukutake, T. and H. Tachinaka, The non-dipole part of the earth's magnetic field, Bull. Earthq. Res. Inst., Univ. Tokyo, 46, 1027-1074, 1968.

YukUTAKE, T. and H. TACHINAKA, Separation of the earth's magnetic field into the drifting and standing parts, Bull. Earthq. Res. Inst., Univ. Tokyo, 47, 65-97, 1969. 